\title{
CONTROL OF NATURAL ZEOLITE PROPERTIES BY MECHANICAL ACTIVATION IN STIRRED MEDIA MILL
}

\begin{abstract}
Due to the special characteristics of zeolites, they can be applied in a very wide range of industries, i.e. agricultural, environmental or water treatment purposes. Generally, high added value zeolite products are manufactured by micro- or nanogrinding. However, these processes require high energy input and cause significant wearing of the mill parts. Therefore, the optimization of zeolite grinding, as well as the control of its properties are of a great importance. In the present paper a Hungarian natural zeolite was mechanically activated in stirred media mill for various residence times in distilled water, meanwhile the particle size distribution and the grinding energy were measured. Additionally, on-line tube rheometer was used to study the rheology of the suspension during the grinding process. The particle interaction and the suspension aggregation stability were detected by zeta-potential measurements. Structural changes due to the mechanical activation process were monitored by FTIR. It was found that the material structure of the zeolite, as well as the rheological behaviour of the zeolite suspension and its aggregation stability had been altered due to the mechanical activation in the stirred media mill. It can be concluded that the zeolite product properties can be modified by mechanical activation in order to produce a high added value tailored material.
\end{abstract}

Keywords: zeolite, mechanical activation, zeta-potential, suspension rheology, FTIR

\section{Introduction}

Zeolites are natural crystalline aluminosilicates. Structurally zeolites are tectosilicates exhibiting an open three-dimensional structure containing cations needed to balance the electrostatic charge of the framework of silica and alumina tetrahedral. The collapse of the crystal structure can be desired in some cases since different strength of Bronsted and Lewis acid and base sites can thus be obtained $[1,2]$. This, in turn, can provide a better catalytic performance [3].

Ion-exchange properties of zeolites can be utilized in agriculture because of their large porosity and high cation-exchange capacity [4]. Additionally, they can be used as both carriers of nutrients and a medium to free nutrients [5]. Furthermore, zeolite incorporation in soil was found to increase crop yields and to promote nutrient uptake efficiency [6]. Other possible uses being investigated include application as a carrier of slow-release fertilizers, insecticides, fungicides, and herbicides, and as a trap for heavy metals in soils [7]. For groundwater remediation, permeable reactive barriers can be used [8] and zeolite can be applied as matrix material due to its high adsorption capacity and ion exchange capability.

Zolzaya et al [9] found that mechano-chemical activation in vibration mill improves cation exchange capacity of natural zeolites. Zeolite structure can be modified by acid or alkaline leaching to create mesopores and hence, to increase the surface area. At the same time Shumskaya et al. [10] suggested that mechano-chemical activation of zeolite improve its reactivity due to the ruptures of the Al-O-Si bonds in zeolite. This wide range of possible applications elevates zeolite among other strategic minerals [11] in Hungary.

Nanosize natural zeolites can be manufactured by micro- or nanogrinding, for example in stirred media mill, which is a high energy density mill. The movement of the grinding medium is carried out by the rotation of the concentrically or eccentrically placed rotor. As a result, the grinding balls colliding with each other are pressed to the mill liners; and collide with the rotor. The particles of the feed material are fractured by impact, pressure, collide and friction stresses [12].

Stirred media mills can be used for various aims, such as mechano-chemical activation of cementitious materials [13]. It can be used also for the enhancement of mass transfer in bio- and chemical processes and ultrafine liberation of semiconductors from glass substrate [14]. These mills can be used in dry [15] or wet [16-20] mode.

The main aim of this research was to investigate the mechanical activation of natural zeolite in a high energy density mill in order to produce submicron final product with narrow size distribution and desired particle interaction properties (stability). Material structure, rheological properties and aggregation stability of the zeolite suspension were examined.

\footnotetext{
INSTITUTE OF RAW MATERIAL PREPARATION AND ENVIRONMENTAL PROCESSING, UNIVERSITY OF MISKOLC, 3515 MISKOLC, HUNGARY 


\section{Materials and methods}

\subsection{Material}

Natural zeolite with material density of $2200 \mathrm{~kg} / \mathrm{m}^{3}$, originated from Rátka deposit, Hungary was used in this study. Its main mineral components were identified as clinoptilolite, orthoclase, cristobalite and quartz by XRD measurement using a Bruker D8 apparatus. Mineral composition is presented in Table 1. Cristobalite and quartz are usually observed in clinoptilolite rich zeolitic tuffs [21].

TABLE 1

Mineral composition of natural zeolite used in the experiments (in $\mathrm{w} / \mathrm{w} \%$, dry basis)

\begin{tabular}{|c|c|}
\hline Phase name & Wt\% Rietveld \\
\hline Clinoptilolite & 38.2 \\
\hline Quartz & 9.6 \\
\hline Cristobalite low & 17.3 \\
\hline Orthoclase & 11.3 \\
\hline Sanidine Na0.16 & 2.8 \\
\hline Illite 2M1 & 7.7 \\
\hline Cristobalite high & 0.8 \\
\hline Mordenite & 1.3 \\
\hline Amorphous & 11.0 \\
\hline Sum & 100.0 \\
\hline
\end{tabular}

The taken natural zeolite sample was preliminary crushed, ground and classified; the maximal particle size of the product was less than $116 \mu \mathrm{m}$. The volume ratio particle size distribution shows bimodal nature (Fig. 3).

\subsection{Methods}

\subsubsection{Mechanical activation by grinding}

Grinding experiments were carried out in a stirred media mill (Netzsch MiniCer, Netzsch GmbH, Germany) in continuous closed circuit mode. The liners of the grinding chamber and the stirrer rotors were made of high wear resistant $\mathrm{ZrO}$ (zirconia). The revolution number of the stirrer was $3000 \mathrm{~min}^{-1}\left(9.3 \mathrm{~ms}^{-1}\right.$ circumferential tip speed) during the experiment. Mill volume in circuit mode is $500 \mathrm{ml}$. With the tube rheometer the volume can reach $805 \mathrm{ml}$. The grinding media size range was 500 $600 \mu \mathrm{m}$ ceramic beads made of yttrium stabilized zirconium oxide (ZY Premium, Sigmund and Lindner, Germany) were used. The filling ratio of grinding media in the milling chamber was $70 \mathrm{v} / \mathrm{v} \%$.

Samples were taken after 5, 10, 20, 30, 60, 120, 240, 360 and 480 min experiment times then analysed using laser particle size analyser (LPSA). Samples were taken from the outflow of the pipe in which the suspension re-enters into the stirrer vessel. The volumetric flow rate was $2.5 \mathrm{e}-05 \mathrm{~m}^{3} / \mathrm{s}$ in case of $190 \mathrm{rpm}$ rotation speed of the pump.
The power draw of the mill was measured online by the Netzsch measuring system and data were registered in the computer. In this way the specific grinding energy could be measured.

\subsubsection{Particle size distribution}

The particle size distribution (PSD) of the raw material and the ground samples was determined by a Horiba LA-950V2 laser particle size analyser (LPSA) in distilled water, using ultrasonic dispersing for $1 \mathrm{~min}$. Furthermore, the ,outer” (geometric) specific surface area (SSA) of the ground samples was calculated by the same LPSA using shape factor 1.0 (Heywood factor).

\subsubsection{Rheology}

In a previous research Faitli et al. [22] introduced an online rheological testing equipment, in which the Netzsch stirred media mill was modified and a supplementary on-line tube rheometer was developed and installed. The laminar pipe flow is a fundamental phenomenon and therefore the tube rheometer is a suitable instrument to measure non-Newtonian rheological behaviour.

The original peristaltic pump of the Netzsch MiniCer was used as the main pump to drive the suspension through the measuring pipe sections. Two measuring pipe sections made from stainless steel were connected serially $\left(D_{1}=10 \mathrm{~mm}\right.$, $\mathrm{L}_{1}=1.6 \mathrm{~m}, \mathrm{D}_{2}=9 \mathrm{~mm}, \mathrm{~L}_{2}=1.6 \mathrm{~m}$ ). If there are two measured pressure loss - flow rate points for a given operational condition, a two parameters non-Newtonian rheological model can be fit. Of-course, the flow rate can be changed and many points of the pseudo shear curve can be measured. The pressure loss of the test pipe sections were measured by no dead space gauge pressure transducers $\left(\Delta \mathrm{p}_{1}=\mathrm{p}_{1}-\mathrm{p}_{2} ; \Delta \mathrm{p}_{2}=\mathrm{p}_{3}-\mathrm{p}_{4}\right)$. For the tube rheometer an independent computer data acquisition system was developed and signals of the pressure transducers No. 1-4 were measured by this auxiliary system with $100 \mathrm{~Pa}$ sensitivity.

The method of evaluation of Bingham plastic tube rheometer data and the validation of tube rheometer data by a rotational rheometer can be found in a previous work [23].

\subsubsection{FTIR}

To follow the structural changes due to the mechanical activation process of zeolite a JASCO FT-IR 4200 type Fourier Transformed Infrared Spectrometer in Reflection mode with diamond ATR PRO470-H condition was used. Three spectra were made from each part-samples and every sample was measured with 3 part-samples. One spectrum averaged of 64 FTIR measurements with $4 \mathrm{~cm}^{-1}$ resolution number. The incident angle was $45^{\circ}$, TGS detector was used and scanning speed was $2 \mathrm{~mm} / \mathrm{sec}$. 


\subsubsection{Zeta-potential}

The $\zeta$-potential measurements were carried out by a ZetaPals device from Brookhaven Instrument Corporation (BIC). The equipment determines zeta-potential using Phase Analysis Light Scattering (PALS), which is an extension of laser electrophoretic light scattering (ELS). $\zeta$-potential was calculated from the electrophoretic mobility using the Smoluchowsky model. To ensure the reproducibility of the measurements, one measurement involved at least 10 several runs. The number of cycles in a run was 20. Zeta potential measurements were carried out within the whole continuous grinding experiment with the freshly taken, as well as with the samples after several hours long steady conditioning. Before the measurements the samples were diluted with de-ionised water and stirred with a magnetic stirrer.

\section{Results and discussion}

\subsection{Mechanical activation by grinding}

The particle size distribution curves of the ground samples are shown in Fig. 1. Rapid decrease in zeolite fineness was observed already after $30 \mathrm{~min}$, followed by a section where particles in a narrower size range were generated. The median and $\mathrm{x}_{80}$ cumulative particle size were $0.21 \mu \mathrm{m}$ and $0.29 \mu \mathrm{m}$ after 120 min residence time respectively. The lowest median and $x_{80}$ particle size were reached after $360 \mathrm{~min}$ residence time, found to be $0.15 \mu \mathrm{m}$ and $0.22 \mu \mathrm{m}$ respectively.

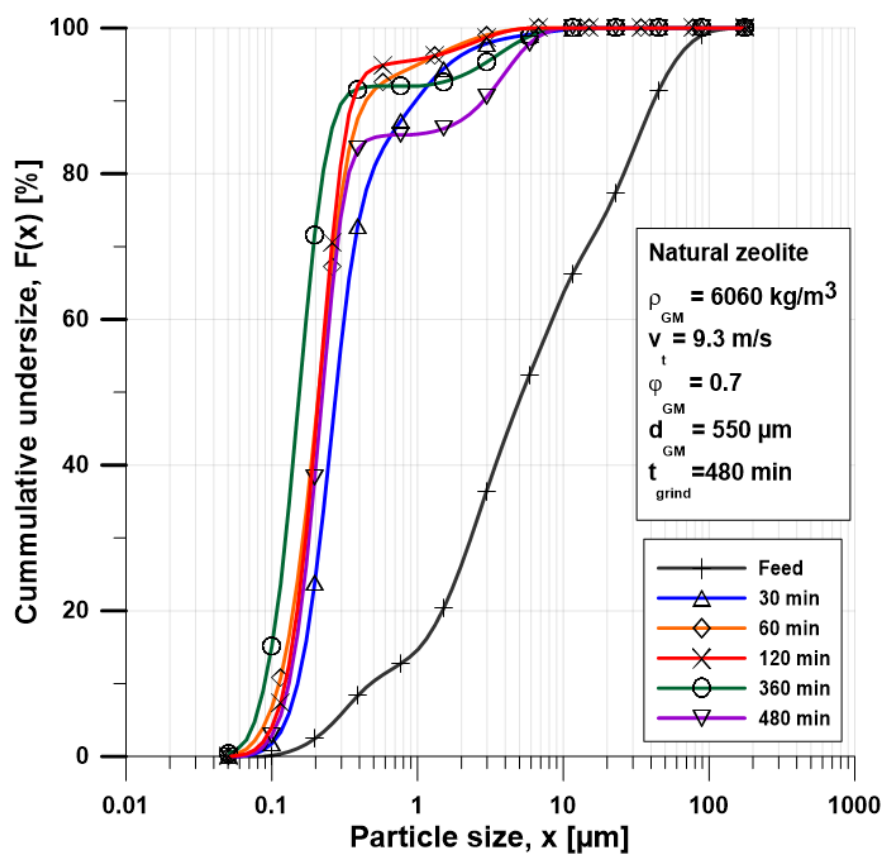

Fig. 1. Particle size distributions of the raw zeolite (feed) and ground products

Fig. 2 represents the $\mathrm{x}_{80}$ and $\mathrm{x}_{95}$ cumulative passing particle size changing during grinding. The $\mathrm{x}_{80}$ characteristic particle size decreased continuously during grinding from $26 \mu \mathrm{m}$ down to $0.33 \mu \mathrm{m}$. Meanwhile, the $\mathrm{x}_{95}$ characteristic particle size decreased from the initial $57 \mu \mathrm{m}$ down to $0.55 \mu \mathrm{m}$ at 90 minutes grinding time, then it was increased up to $3.0 \mu \mathrm{m}$ at 240 minutes grinding time then it was nearly constant.

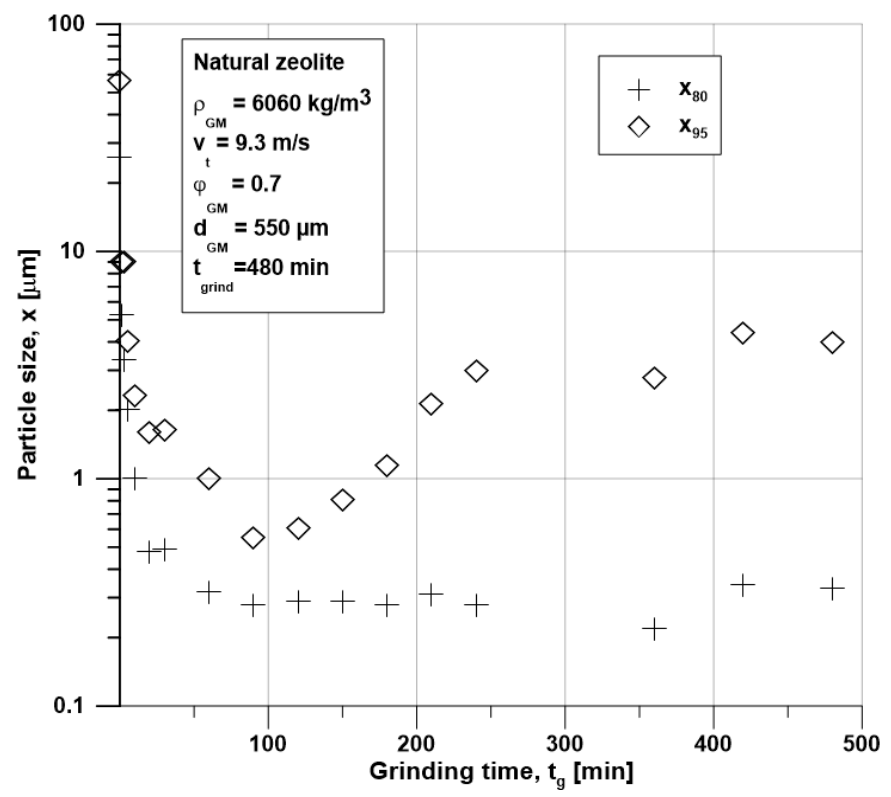

Fig. 2. The $x_{80}$ and $x_{95}$ particle size of zeolite during grinding

In Fig. 3 it can be seen that bimodal nature of the histogram of the raw zeolite remained characterising in the first stage of grinding, but the mode values were significantly shifted to the submicronic size range. It can also be seen clearly that not only the surface attrition, but breakage of the particles occurred in the grinding process.

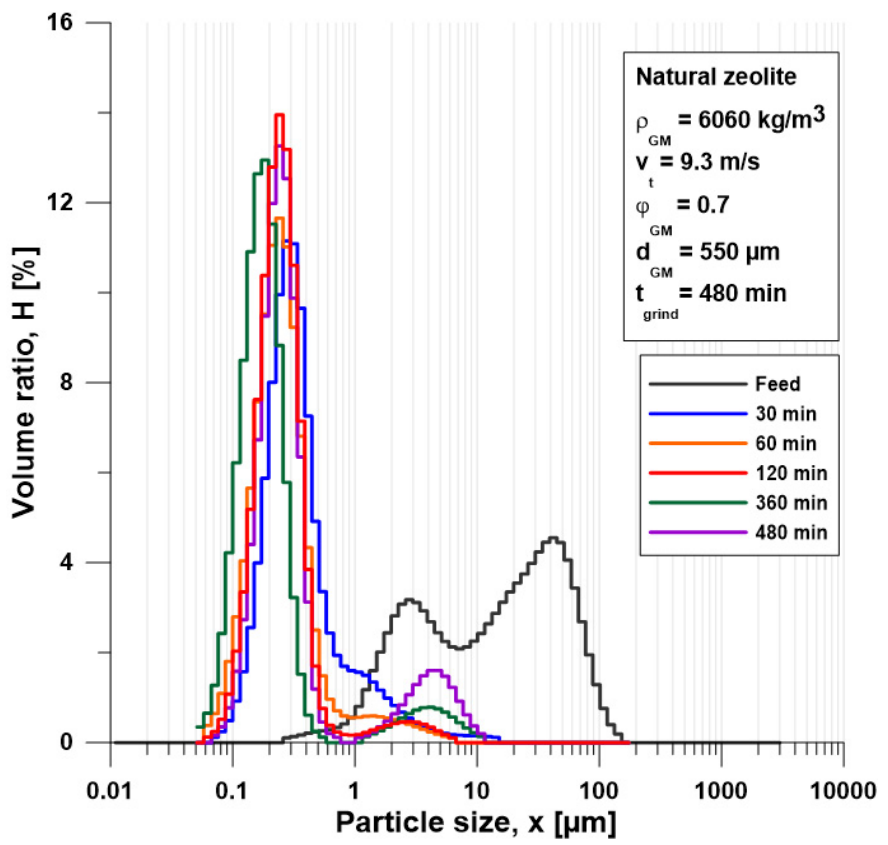

Fig. 3. Histograms of raw zeolite and ground products

The calculated specific surface area as a function of the specific energy input (Fig. 4) initially increases near linearly 


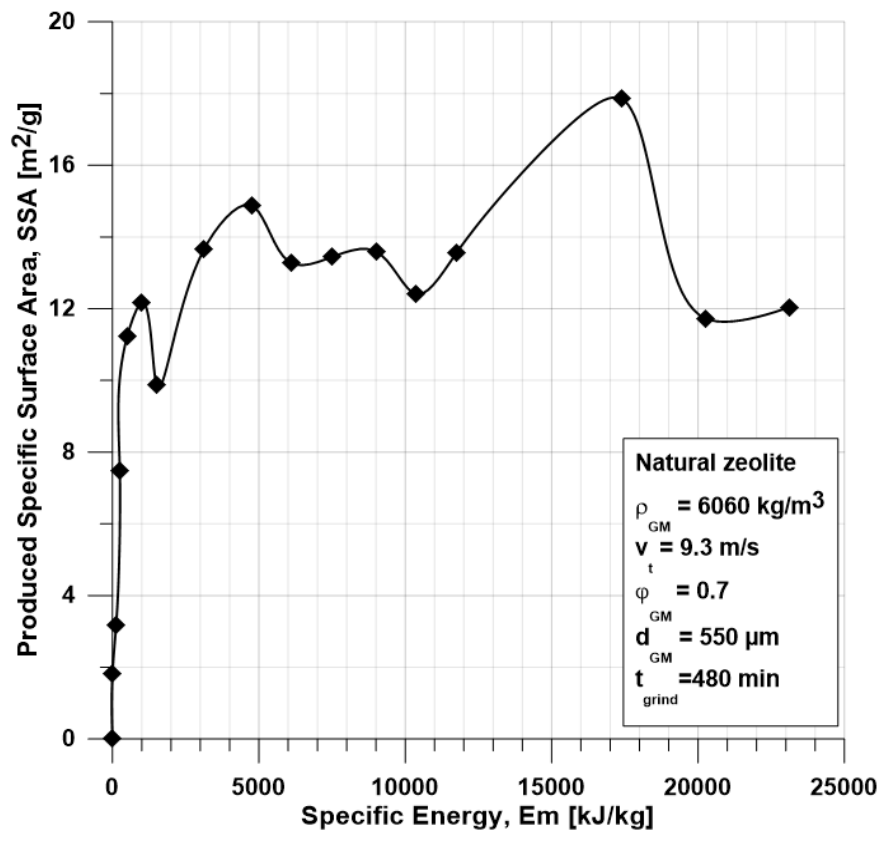

Fig. 4. The calculated specific surface area as a function of the specific energy

(until $1000 \mathrm{~kJ} / \mathrm{kg}, \mathrm{SSA}=12 \mathrm{~m}^{2} / \mathrm{g}$ ), this interval is generally referred as the Rittinger section of grinding kinetics. This is followed by a fluctuating curve shape indicating the aggregation or agglomeration of the primary zeolite particles and the generation of secondary ones. However, the maximum SSA, as high as $18 \mathrm{~m}^{2} / \mathrm{g}$, was reached at $17,000 \mathrm{~kJ} / \mathrm{kg}$ specific energy after 360 min grinding time.

\subsection{Rheology}

Fig. 5 shows the apparent viscosity of the suspension as a function of residence time in case of the tube rheometer test using one measuring tube. As it is well known the apparent vis-

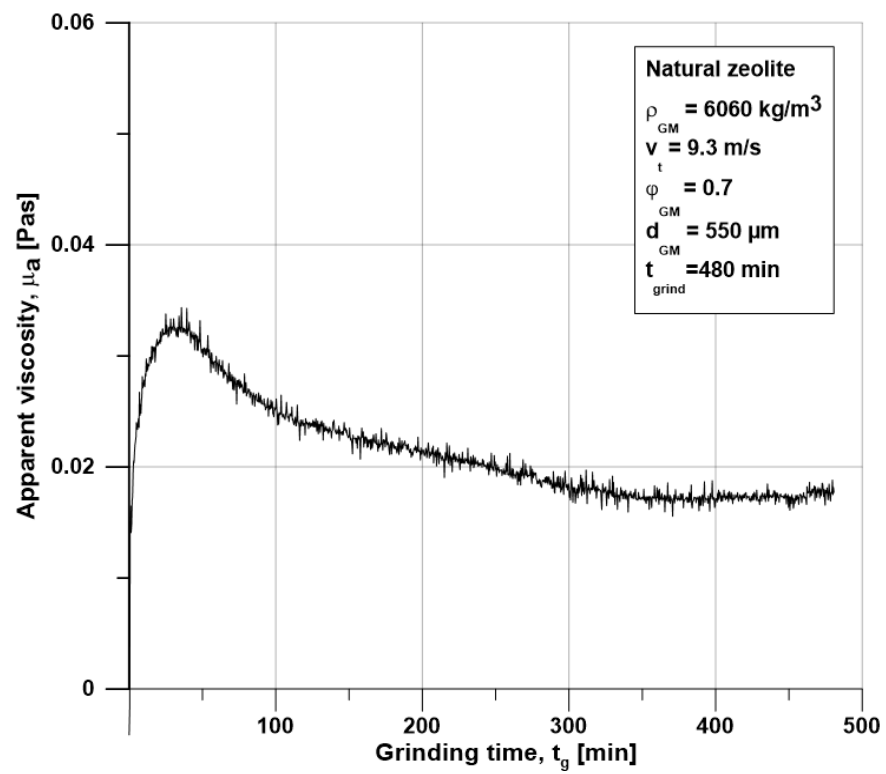

Fig. 5. Apparent viscosity of the ground suspension as function of time cosity is not a rheological material parameter like the absolute viscosity of Newtonian fluids. The magnitude of the apparent viscosity is proportional with the inner resistance of the fluid against the movement. The inner viscous resistance of the suspension increased initially, and at 35 minutes it reached a maximal peak value of 0.034 Pas. After this peak, it started to decrease and after 300 minutes stagnated until $\mathrm{t}=480$ minutes.

After 480 minutes of continuous grinding the mill was stopped and an independent tube rheometer test was performed. During this rheological test the revolution number of the peristaltic pump was systematically varied, so different flow rates were set in the measuring tube section. The measured pseudo shear curve is shown in Fig. 5.

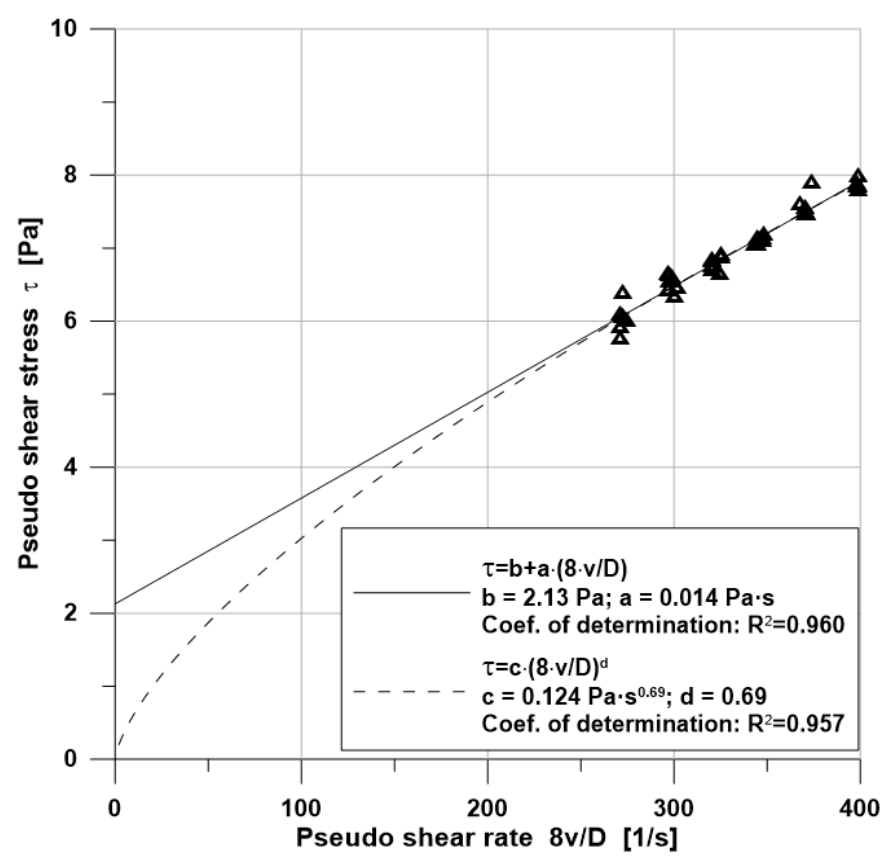

Fig. 6. The measured pseudo shear curve after 480 min long grinding

Fig. 6 shows that there are measured shearing points only in the $270-4001 / \mathrm{s}$ pseudo shear rate range. It is not possible to measure at zero or near zero flow velocity (shear rate) with the tube rheometer. Based on Fig. 6 the Bingham plastic linear and the Power Law exponential (shear thinning) rheological models could be applicable. The linear model fits slightly better because the coefficient of determination is a little bit higher; therefore the suspension can be considered as being a Bingham plastic fluid. The yield stress is $\tau_{\mathrm{o}}=3 \cdot \mathrm{b} / 4=1.6 \mathrm{~Pa}$ and the plastic viscosity is $\eta=\mathrm{a}=14 \mathrm{mPa} \cdot \mathrm{s}$.

\subsection{FTIR}

FTIR spectra is suitable to acquire information about the structure, structure change and the cation substitution $\left(\mathrm{Si}^{4+}\right.$ by $\mathrm{Al}^{3+}$ ) in the tetrahedral sites of zeolite minerals [24-28]. The results of FTIR measurements are shown in Fig. 7 where the characteristic bonds [29] are marked and the results are summarized in Table 2. 
The exact position (peak wavenumber) of bonds observed in FTIR spectra for raw and ground zeolite

\begin{tabular}{|c|c|c|c|c|c|c|c|}
\hline \hline Sample & Feed & $\mathbf{3 0 ~} \mathbf{m i n}$ & $\mathbf{6 0} \mathbf{~ m i n}$ & $\mathbf{1 2 0} \mathbf{m i n}$ & $\mathbf{2 4 0} \mathbf{m i n}$ & $\mathbf{3 6 0} \mathbf{m i n}$ & $\mathbf{4 8 0} \mathbf{m i n}$ \\
\hline $\begin{array}{c}\text { Symmetric stretching vibration } \\
(\mathrm{Si}-\mathrm{O}-\mathrm{Si} \text { and Al-O-Si) }\end{array}$ & 594 & 590 & 594 & 595 & 592 & 592 & $553,565,591$ \\
\hline $\begin{array}{c}\text { Symmetric stretching vibration } \\
(\mathrm{Si}-\mathrm{O}-\mathrm{Si} \text { and Al-O-Si) }\end{array}$ & 729 & 721 & 720 & 721 & 716 & 714 & 722 \\
\hline Symmetric stretching vibration of Si-O-Si(Al) & 795 & 796 & 795 & 795 & 794 & 793 & 792 \\
\hline Asymmetric stretching vibration (Si(Al-O) & 1011 & 1011 & 1018 & 1014 & 1015 & 1021 & 1012,1093 \\
\hline Bending vibrations (HOH) & 1631 & 1633 & 1630 & 1631 & 1643 & 1639 & 1636,1650 \\
\hline Stretching vibration (-OH, HOH) & 3407 & 3417 & 3432 & 3421 & 3404 & 3401 & 3269,3365 \\
\hline
\end{tabular}

Bands due to the Si-O-Si and Si-O-Al vibrations occur in the region $1200-950 \mathrm{~cm}^{-1}$, where the strongest vibration band appears at $1010 \mathrm{~cm}^{-1}$. It was found in all zeolites due to the internal tetrahedron vibrations and is assigned to a T-O stretching mode [30]. This band (at $1010 \mathrm{~cm}^{-1}$ ) is significant for the estimation of the aluminium content in the crystalline framework. It depends on the framework $\mathrm{nSi} / \mathrm{nAl}$ ratio and is considered to be determination for the $\mathrm{Al}$ atoms per unit. It shifts to a lower wavenumber with increasing number of $\mathrm{Al}$ atoms in the framework tetrahedral sites [31]. Moreover, substitution of $\mathrm{Al}^{3+}$ for $\mathrm{Si}^{4+}$ decreases T-O-T angle, and the resulting frequency is lower, due to the weaker character and increased length of the Al-O bond, the force constant for the mode in an Al-Si-O bond is lower than the corresponding mode is a Si-O-Si linkage. Thus, it is expected that the more $\mathrm{Al}^{3+}$ atoms are extracted from the framework, the more this band will shift to higher wave number values in the FTIR spectra [24]. At the activated sample after $60 \mathrm{~min}$ of grinding it shifts to $1018 \mathrm{~cm}^{-1}$ and after $360 \mathrm{~min}$ to $1021 \mathrm{~cm}^{-1}$.

In all FTIR spectra, the bands are quite broad, which is owing to the fact that all samples consist of a variety of crystalline phases and amorphous mass [32]. A weak band at $795 \mathrm{~cm}^{-1}$ appears in all spectra and can be assigned to quartz or amorphous $\mathrm{SiO}_{2}$ stretching bond vibrations. The vibrations in the region $1600-3700 \mathrm{~cm}^{-1}$ can be assigned to the presence of zeolite water. The bands are attributed to the hydrogen bonding of the water molecule to surface oxygen $\left(3407 \mathrm{~cm}^{-1}\right)$ and to the bending mode of water $\left(1631 \mathrm{~cm}^{-1}\right)$ [24].

In the region $600-800 \mathrm{~cm}^{-1}$ ( 590 and $720 \mathrm{~cm}^{-1}$ ), bands attributed to exchangeable cations may occur, but bands due to pseudocrystallic vibrations may be confusing $[32,33]$ These bands are clearly lower intensity in the FTIR spectra of 360 and $480 \mathrm{~min}$ samples - as compared to feed sample - as these samples could suffer crystallinity loss. These vibrations are insensitive to the nature of the channel cations, as well as to the $\mathrm{Si} / \mathrm{Al}$ ratio.

New bonds appeared in case of the $480 \mathrm{~min}$ ground sample as symmetric ( $\mathrm{Si}-\mathrm{O}-\mathrm{Si}(\mathrm{Al}))$ at $553,565 \mathrm{~cm}^{-1}$, asymmetric stretching vibrations ( $\mathrm{Si}(\mathrm{Al}-\mathrm{O})$ ) at $1093 \mathrm{~cm}^{-1}$, bending vibrations $(\mathrm{HOH})$ at $1650 \mathrm{~cm}^{-1}$ and stretching vibration $(-\mathrm{OH}, \mathrm{HOH})$ at 3269 and $3365 \mathrm{~cm}^{-1}$. The shoulder at $1093 \mathrm{~cm}^{-1}$ is due to the presence of cristobalite and smectite, with the possible contribution of amorphous silica [24].

Peak shift also can be observed. The most significant shifts are in case of symmetric stretching vibrations ( $\mathrm{Si}-\mathrm{O}-\mathrm{Si}(\mathrm{Al}))$ and

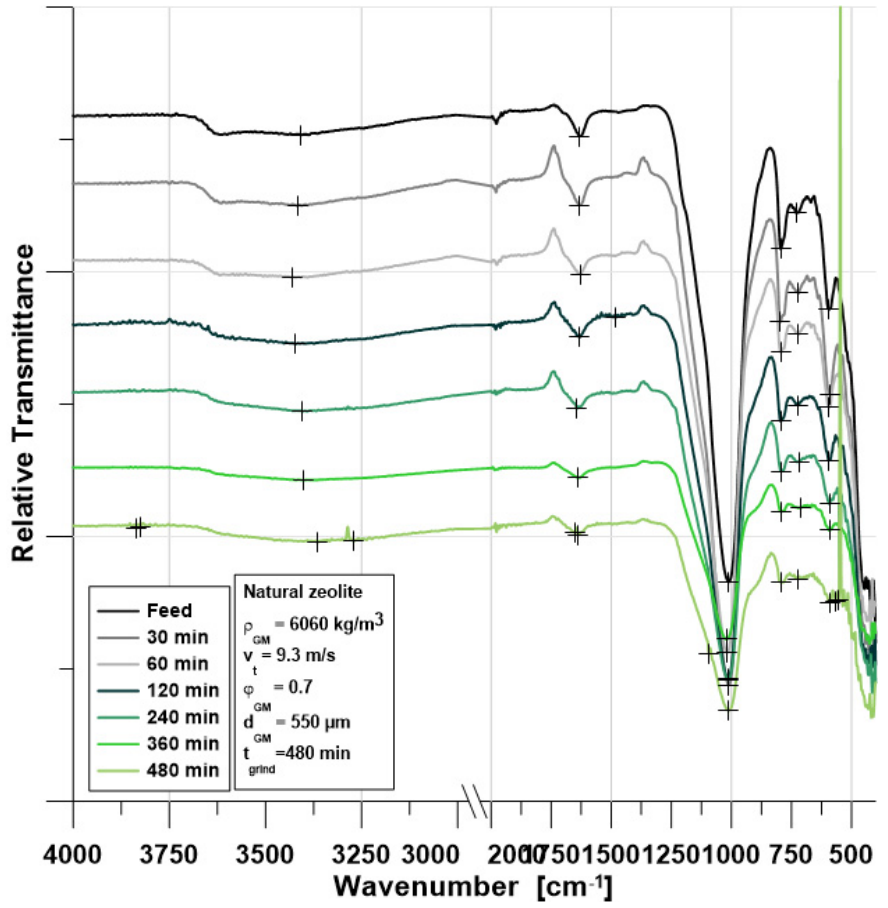

Fig. 7. FTIR spectra of zeolite samples during grinding

stretching vibration $(-\mathrm{OH}, \mathrm{HOH})$ at $3300-3400 \mathrm{~cm}^{-1}$. Based on these results it can be stated that the material structure of the zeolite sample had been changed due to the mechanical activation.

Fig. 8 represents the main peaks shifted during the grinding. The absolute differences between the ground samples peaks' wavenumber and the feed material peak's wavenumber are plotted as a function of grinding time. It can be observed that the $\mathrm{HOH}$ bending vibration at $\sim 1630 \mathrm{~cm}^{-1}$ wavenumber peak changed in the opposite way as compared with the stretching vibration $-\mathrm{OH}, \mathrm{HOH}$ at $\sim 3400 \mathrm{~cm}^{-1}$. Asymmetric stretching vibration ( $\mathrm{Si}(\mathrm{Al}-\mathrm{O}))$ at $1011 \mathrm{~cm}^{-1}$ also shifted to a higher wave number values especially at 30 and 360 min resulted from $\mathrm{Al}^{3+}$ atoms are extraction from the framework.

Fig. 9 shows intensity change of FTIR peaks compared with the initial state. The intensity change is the most significant at the asymmetric stretching vibration $\left(\mathrm{Si}(\mathrm{Al}-\mathrm{O})\right.$ at $\sim 1010 \mathrm{~cm}^{-1}$ and the symmetric stretching vibration $(\mathrm{Si}-\mathrm{O}-\mathrm{Si}$ and $\mathrm{Al}-\mathrm{O}-\mathrm{Si})$ at $590 \mathrm{~cm}^{-1}$ during grinding. They show three intensity maxima at 30,120 and 360 minutes grinding time as compared to the feed material. The highest maximum is at 360 minutes in both cases, 


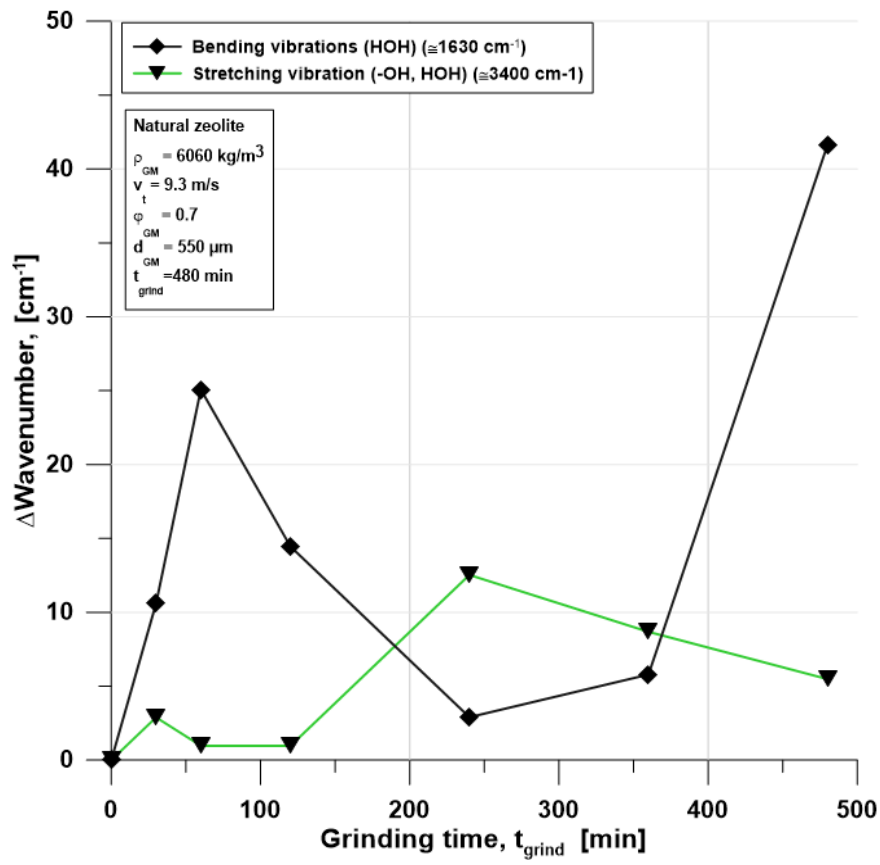

Fig. 8. FTIR peak shifting during grinding at 1630 and $3400 \mathrm{~cm}^{-1}$ wavenumber

16 and $8 \% \mathrm{~T}$. The first two intensity maxima coincide with the i.e.p.-s, while the third one with the minimum of the $\xi=\xi(\mathrm{t})$ curve obtained for the freshly ground sample. Nevertheless, the first intensity maximum, as well as the first i.e.p. coincides with the peak point of the apparent viscosity. Furthermore, X-ray diffraction measurement for the precise determination of the mineralogical phase changes will be carried out in near future.

\subsection{Zeta-potential}

Zeta-potential measurements were carried out aiming at the revelation of possible changes in the surface charge and sign, as well as in the aggregation stability of zeolite during the $480 \mathrm{~min}$ long continuous micro-grinding [14,34-37].

The results are shown in Fig. 10. It can be seen in case of the freshly ground samples (green curve) that zeta-potential of the zeolite in the first $60 \mathrm{~min}$ of retention time of grinding follows a minimum-curve with the lowest $\zeta$-potential of $-2.35 \mathrm{mV}$. It reaches the highest value of $5.1 \mathrm{mV}$ at $\mathrm{t}=60 \mathrm{~min}$. During the first $60 \mathrm{~min}$ there is no aggregation stability in the system, the particle-particle aggregation is the most likely here. During the next $300 \mathrm{~min}$ the significant drop in $\zeta$-potential was observed, down to $-32.64 \mathrm{mV}$ with the isoelectric point, the i.e.p. at $\mathrm{t}=125 \mathrm{~min}$. In the grinding time period between 150 and $360 \mathrm{~min}$ the system is aggregatively stable due to the significant electrostatic repulsion of the negatively charged zeolite particles. In the last tested time period the $\zeta$-potential increases again up to $-11.7 \mathrm{mV}$. The curve trend shows that the aggregation stability might turn into instability during possible further grinding. The initial $\mathrm{pH}$-value was as high as 8.34 , and it dropped down to $\mathrm{pH}$ $=7.87$ during the grinding.

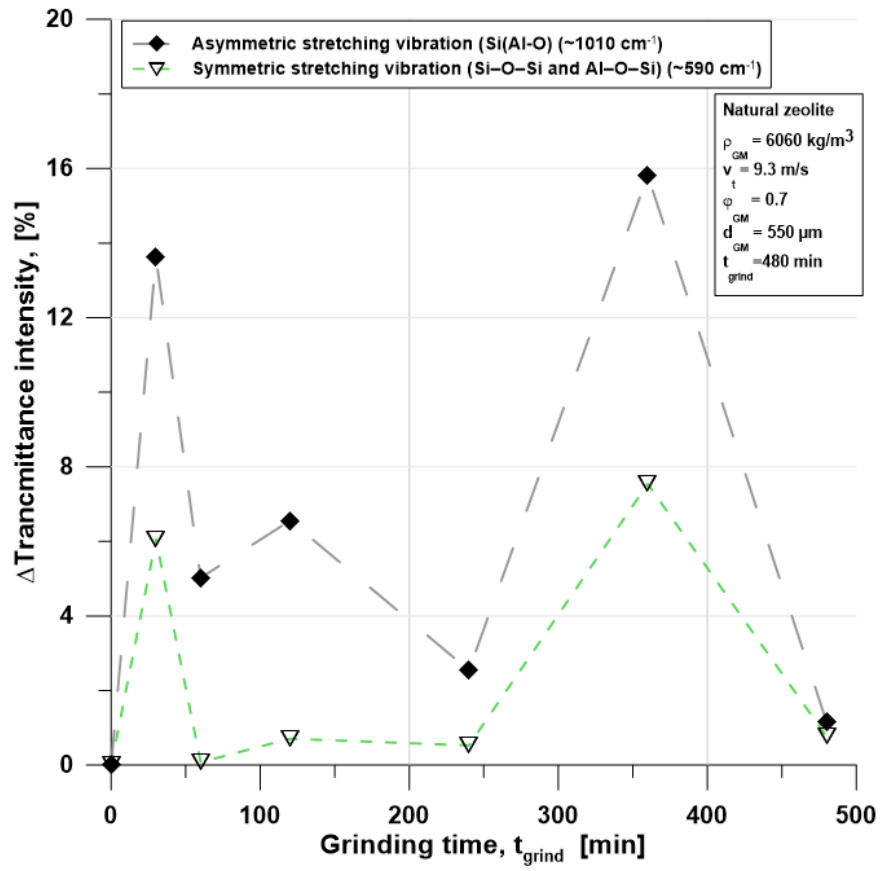

Fig. 9. FTIR peak intensity changing during grinding at 1010 and 590 $\mathrm{cm}^{-1}$ wavenumber

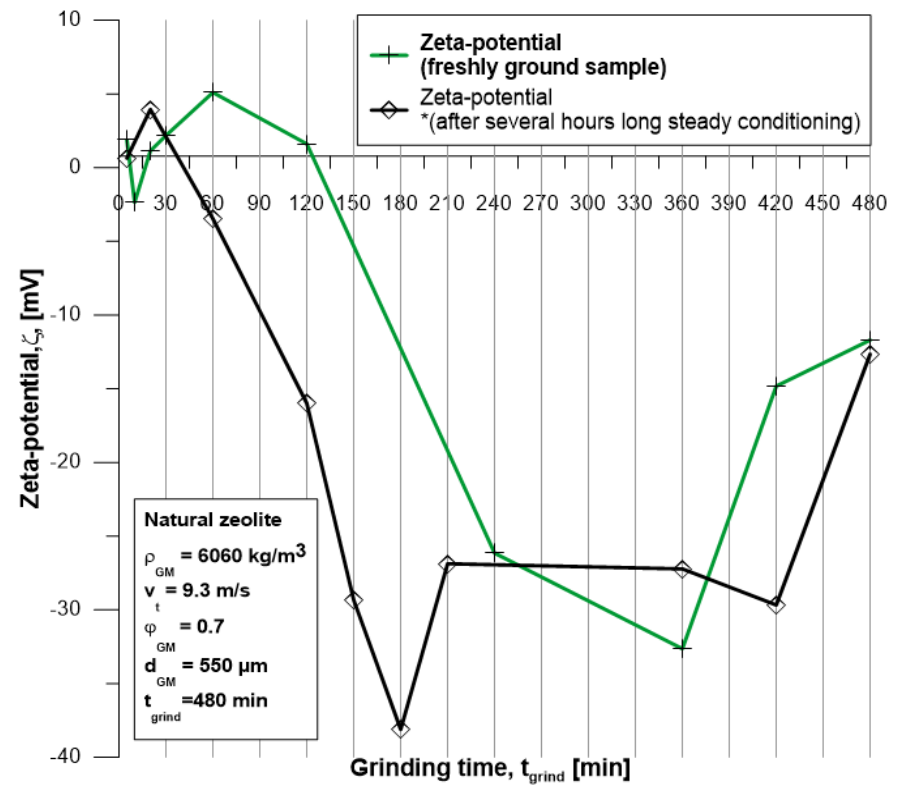

Fig. 10. Zeta-potential of zeolite during the continuous micro-grinding

The $\zeta$-potential curve obtained for the several hours long steady conditioning looks like the green curve would be shifted to the left with the first minimum at $\mathrm{t}=180 \mathrm{~min}$ ( $\zeta$-potential as low as $-38.11 \mathrm{mV})$. Although, it has a second minimum as well $(-29.67 \mathrm{mV}$ at $420 \mathrm{~min})$ and crosses the green curve twice until reaches it.

It can be revealed and concluded, that at the early kinetic stage of the grinding of zeolite mostly the $=\mathrm{Si}=\mathrm{O}$ bonds suffer breakage, while at continuous grinding longer than $125 \mathrm{~min}$, predominantly the $=\mathrm{Al}-\mathrm{O}$ - bonds are breaking providing a high negative surface charge, i.e. the aggregation stability. The even longer continuous grinding leads to the surplus of surface en- 
ergy in such extend that the system tends to compensate it, i.e. zeta-potential increases and the aggregation might take place.

The zeolite samples after different grinding time were then steady conditioned for several, from 2.5 up to 15 hours. The zetra-potential curve of the steady conditioned samples is plotted against the real grinding time and shown in black. It can be seen that there is a shift of zeta-curve to the left below $t=240 \mathrm{~min}$. It is very likely that some kind of restructuring of the microground structure of zeolite takes place in this interval. So that, the obtained structure alteration of the zeolite is a reversible one in this interval. At higher grinding time the difference between the two zeta-curves is not significant.

The correlation between the zeta-potential and the apparent viscosity of the tested zeolite system is shown in Fig. 11.

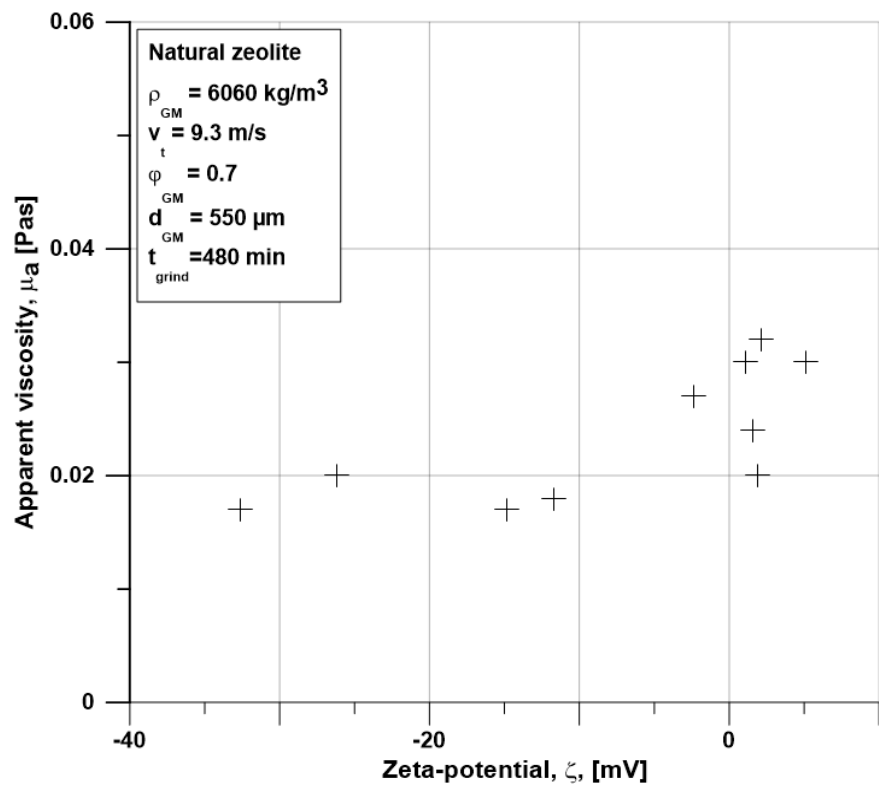

Fig. 11. Zeta potential as a function of apparent viscosity

In the tested interval increasing from the aggregation stability due to the negative surface charge, up to the aggregation non-stability $(-5 \ldots+5 \mathrm{mV})$ of the $\xi$-potential of freshly ground samples, the apparent viscosity grows.

Zeolite at the examined weak alkaline conditions $(\mathrm{pH}=$ $7.87 \ldots 8.34$ ) has slightly positive surface charge. However, after 60 minutes of grinding the positive charge became slightly higher. As a consequence of the grinding the newer and newer surface appears, as well as the rupture of chemical bonds occurs. In the FTIR spectra of the freshly ground sample at $60 \mathrm{~min}$ the band at $1011 \mathrm{~cm}^{-1}$ shifted to the left (higher wave number values), in terms of literature due to the decrease in number of $\mathrm{Al}^{3+}$ atoms in the framework tetrahedral sites [24,30,31], so that $\mathrm{Si}^{4+}$ become potential-determining ions.

The next point, where more $\mathrm{Al}^{3+}$ atoms are supposed to be broken off from the framework, in accordance with the FTIR spectra of the $360 \mathrm{~min}$ sample. At this point the specific surface area has maximum $\left(18 \mathrm{~m}^{2} / \mathrm{g}\right)$ and the $\mathrm{x}_{80}$ characteristic particle size has minimum $(0.22 \mu \mathrm{m})$ value. It follows that the most surface during grinding formed at this grinding time. In this point the zeta-potential has minimum value which indicates negatively charge ions and groups such as $\mathrm{OH}^{-}, \mathrm{O}^{2-}, \mathrm{Si}-\mathrm{O}^{2-}$ closely approaches the surface and adsorb on it. As a result of further grinding, the aggregation or agglomeration can occur as well, this is proved by the increasing of specific surface area and decreasing of zeta-potential and characteristic particle size $\left(\mathrm{x}_{80}\right.$ and $\left.\mathrm{x}_{95}\right)$.

The relationship between the apparent viscosity and the zeta-potential can be observed quantitatively, since both phenomena originate from the interaction between solid-solid and solid-liquid particles. Around the i.e.p. of zeta-potential the apparent viscosity has maximum value (Fig. 11). Because of aggregation, the apparent viscosity should increase.

\section{Conclusions}

Nano zeolite was successfully produced using Netzsch MiniCer stirred media mill. The mode size of $200 \mathrm{~nm}$ and the highest geometric specific surface area of $18 \mathrm{~m}^{2} / \mathrm{g}$ was achieved after 360 min continuous grinding. It was experimentally proved that the material structure of zeolite, the rheological property and the aggregation stability of the zeolite suspension have been altered due to the mechanical activation in the stirred media mill. The interrelations between the structural changes, the zetapotential, as well as the rheological behaviour were revealed. The obtained results are very promising from the point of view of micro- and nanogrinding of tailored products.

\section{Acknowledgement}

The described work was carried out of the Centre of Excellence in Sustainable Natural Resource Management at the Faculty of Earth Science and Engineering, University of Miskolc.

\section{REFERENCES}

[1] J. Xie, S. Kaliaguine, Zeolite ball milling as a means of enhancing the selectivity for base catalyzed reactions 148, 415-423 (1997).

[2] P.A. Zielinski, A. Van Neste, D.B. Akolekar, S. Kaliaguine, Effect of high-energy ball milling on the structural stability, surface and catalytic properties of small-, medium- and large-pore zeolites, Microporous Mater. 5, 123-133 (1995).

[3] K. Akçay, A. Sirkecioğlu, M. Tatlıer, Ö.T. Savaşçı, A. Erdem-Şenatalar, Wet ball milling of zeolite HY, Powder Technol. 142, 121-128 (2004).

[4] M. Reháková, S. Čuvanová, M. Dzivák, J. Rimár, Z. Gaval’Ová, Agricultural and agrochemical uses of natural zeolite of the clinoptilolite type, Curr. Opin. Solid State Mater. Sci. 8, 397-404 (2004).

[5] P. Misaelides, Application of natural zeolites in environmental remediation: A short review, Microporous Mesoporous Mater. 144, 15-18 (2011).

[6] R. Malekian, J. Abedi-Koupai, S.S. Eslamian, Influences of clinoptilolite and surfactant-modified clinoptilolite zeolite on nitrate 
leaching and plant growth, J. Hazard. Mater. 185 (2011) 970-976. doi:10.1016/j.jhazmat.2010.09.114.

[7] K. Ramesh, D.D. Reddy, Advances in Agronomy Chapter Four-Zeolites and Their Potential Uses in Agriculture, in: Adv. Agron., 2011: pp. 219-241. doi:10.1016/B978-0-12-386473-4.00004-X.

[8] I. Gombkötő, T. Madarász, J. Lakatos, P. Szücs, Using Lignite as Remediation Agent at Post Mineral Processing Sites, in: XXVI Int. Miner. Process. Congr., Indian Institute of Metals, New Delhi, India, 2012: pp. 1629-1636. isbn: 81-901714-3-7.

[9] T. Zolzaya, B. Davaabal, Z. Ochirbat, G. Oyun-Erdene, A. Minjigmaa, J. Temuujin, The mechanochemical activation study of Tsagaan-tsav zeolite, Mong. J. Chem. 12, 98-101 (2011). doi:10.5564/mjc.v12i0.181.

[10] L. Shumskaya, Y.A. Kirillova, T.S. Yusupov, Controlled changes in technological properties of phosphates in mechanical activation with zeolites, J. Min. Sci. 35 (1999) 96-100. doi:10.1007/ BF02562452.

[11] J. Földessy, B. Csőke, I. Gombkötő, N. Zajzon, Szegény gazdag ország Magyarország alig ismert stratégiai nyersanyagforrásai, Természet Világa. 146, 125-127 (2015).

[12] Á. Rácz, Theoretical basis of modeling wet grinding in stirred media mills, Magy. Kémikusok Lapja. LXVII, 290-294 (2012).

[13] G. Mucsi, Á. Rácz, V. Mádai, Mechanical activation of cement in stirred media mill, Powder Technol. 235, 163-172 (2013). doi:10.1016/j.powtec.2012.10.005.

[14] L. Bokányi, Innovative mineral processing techniques in waste recycling, in: I. Üner, A. Vedat, S. Sezai (Eds.), Proc. 14 Th Int. Miner. Process. Symp., Turkish Mining Development Foundation, Kusadasi, Turkey, 2014: p. inv55-inv62.

[15] Á. Rácz, B. Csőke, Application of the product related stress model for product dispersity control in dry stirred media milling, Int. J. Miner. Process. 157, 28-35 (2016). doi:10.1016/j.minpro.2016.09.005.

[16] C. Knieke, C. Steinborn, S. Romeis, W. Peukert, S. Breitung-Faes, A. Kwade, Nanoparticle production with stirred-media mills: Opportunities and limits, Chem. Eng. Technol. 33, 1401-1411 (2010). doi:10.1002/ceat.201000105.

[17] F. Stenger, S. Mende, J. Schwedes, W. Peukert, Nanomilling in stirred media mills, Chem. Eng. Sci. 60, 4557-4565 (2005). doi:10.1016/j.ces.2005.02.057.

[18] S. Romeis, J. Schmidt, W. Peukert, Mechanochemical aspects in wet stirred media milling, Int. J. Miner. Process. 156, 24-31 (2016). doi:10.1016/j.minpro.2016.05.018.

[19] M.A. Azad, A. Afolabi, N. Patel, R. Davé, E. Bilgili, Preparation of stable colloidal suspensions of superdisintegrants via wet stirred media milling, Particuology. 14, 76-82 (2014). doi:10.1016/j. partic.2013.07.008.

[20] E. Bilgili, R. Hamey, B. Scarlett, Nano-milling of pigment agglomerates using a wet stirred media mill: Elucidation of the kinetics and breakage mechanisms, Chem. Eng. Sci. 61, 149-157 (2006). doi:10.1016/j.ces.2004.11.063.

[21] F. Kristály, S. Orbán, A. Kovács, Clinoptilolite Tuff at Racoş and Mateiaş (Perşani MTS, Central Romania), in: I. Macek (Ed.), Proc. Int. Symp. CEMC 2014 4th Cent. Mineral. Conf.-CEMC 2014, Brno, 64-65 (2014) (ISBN:978-80-210-6832-2).
[22] J. Faitli, K. Bohács, G. Mucsi, Online Rheological Behaviour Testing of Stirred Media Milled Suspensions, in: M. Evertsson, E. Hulthén, J. Quist (Eds.), Proc. 14th Eur. Symp. Comminution Classif., Gothenburg, Sweden, 87-93 (2015).

[23] J. Faitli, K. Bohács, G. Mucsi, Online rheological monitoring of stirred media milling, Powder Technol. (2016). doi:http://dx.doi. org/10.1016/j.powtec.2016.12.021.

[24] K. Elaiopoulos, T. Perraki, E. Grigoropoulou, Mineralogical study and porosimetry measurements of zeolites from Scaloma area, Thrace, Greece, Microporous Mesoporous Mater. 112, 441-449 (2008). doi:10.1016/j.micromeso.2007.10.021.

[25] D. Zhao, K. Cleare, C. Oliver, C. Ingram, D. Cook, R. Szostak, L. Kevan, Characteristics of the synthetic heulandite-clinoptilolite family of zeolites, Microporous Mesoporous Mater. 21, 371-379 (1998). doi:10.1016/S1387-1811(98)00131-0.

[26] D.W. Breck, Zeolite molecular sieves: structure, chemistry, and use, Wiley, 1973. https://books.google.co.in/books?id=aY0vAQAAIAAJ.

[27] W. Mozgawa, M. Król, K. Barczyk, FT-IR studies of zeolites from different structural groups, Chemik. 65, 671-674 (2011).

[28] W. Mozgawa, The relation between structure and vibrational spectra of natural zeolites, J. Mol. Struct. 596, 129-137 (2001). doi:10.1016/S0022-2860(01)00741-4.

[29] D. Panias, I.P. Giannopoulou, T. Perraki, Effect of synthesis parameters on the mechanical properties of fly ash-based geopolymers, Colloids Surfaces A Physicochem. Eng. Asp. 301, 246-254 (2007). doi:10.1016/j.colsurfa.2006.12.064.

[30] T. Perraki, A. Orfanoudaki, Mineralogical study of zeolites from Pentalofos area, Thrace, Greece, Appl. Clay Sci. 25, 9-16 (2004). doi:10.1016/S0169-1317(03)00156-X.

[31] K. Elaiopoulos, T. Perraki, E. Grigoropoulou, Monitoring the effect of hydrothermal treatments on the structure of a natural zeolite through a combined XRD, FTIR, XRF, SEM and N2-porosimetry analysis, Microporous Mesoporous Mater. 134, 29-43 (2010). doi:10.1016/j.micromeso.2010.05.004.

[32] M.T. Blanco Varela, S. Martínez Ramírez, I. Ereña, M. Gener, P. Carmona, Characterization and pozzolanicity of zeolitic rocks from two Cuban deposits, Appl. Clay Sci. 33, 149-159 (2006). doi:10.1016/j.clay.2006.04.006.

[33] M.P. Elizalde-González, J. Mattusch, R. Wennrich, P. Morgenstern, Uptake of arsenite and arsenate by clinoptilolite-rich tuffs, Microporous Mesoporous Mater. 46, 277-286 (2001). doi:10.1016/ S1387-1811(01)00308-0.

[34] R.J.Hunter,Zeta Potential in Colloid Science,Academic Press,(1981).

[35] L. Bokányi, T.I. Török, The Fundamentals of Metals Recycling by Flotation or Flotation Related Methods, in: Proc. XX. Int. Miner. Proc. Congr., Aachen, Germany, n.d.

[36] L. Bokányi, Effect of CuSO4 on surface properties and recycling flotation of copper and lead, in: Proc. XXIII Int. Miner. Process. Congr. 3, 2147-2151 (2006).

[37] L. Bokányi, A. Bruncszlik, Fundamental research on surface properties of fluorite originated from mining tails to establish a recycling technology, in: S. Sen Üner Ipekoglu, Vedat Arslan (Ed.), Proc. 14 Th Int. Miner. Process. Symp. 343-351 (2014) 975-441-436-3. 